\title{
POST-QUAKE SMALL ITALIAN HISTORICAL CENTRES: URBAN RESILIENCE BETWEEN RHETORICS AND REALITY. THE CASE STUDY OF NOCERA UMBRA AFTER THE 1997 UMBRIA-MARCHE EARTHQUAKES
}

\author{
E. CIANCI ${ }^{*}{ }^{*}$, C. FONTANA ${ }^{1}$, G. OCCHIPINTI ${ }^{1}$ AND G. ROMAGNOLI ${ }^{1}$ \\ ${ }^{1}$ Institute of Environmental Geology and Geoengineering (IGAG), \\ Italian National Research Council (CNR) Rome, Italy \\ e-mail: \{eleonora.cianci, cora.fontana, gino.romagnoli, giuseppe.occhipinti\}@igag.cnr.it , \\ (*corresponding author)
}

Keywords: Resilient urban planning, Building heritage, Site effects, Post-earthquake reconstruction

\begin{abstract}
The small and medium Italian historical centres are characterized, among other things, by reconstruction that have occurred over the centuries after earthquakes. While earthquakes determine structural damages, human losses and loss of the functionality of an urban system above all, they may create, at the same time, new opportunities if the urban and socio-economical structures are improved during the reconstruction processes as a whole. These processes and the optimal implementation of planning models within them is not straightforward [1], due to that several issues emerge as a challenge of the reconstruction programmes (decision-making processes, general vision for the entire urban system for instance). According to the literature, although a unique definition has not still been coined, resilience can be defined as the capacity of a system (a city) to withstand and restore after a shocking episode (an earthquake). Mainly in the context of cities [2], some approaches have been framed and experimented by other authors [3, 4, 5]. Starting from a short literature review, focuses on theories and methodological approaches to evaluate urban resilience, this work analyses - through an interdisciplinary approach - the case study of Nocera Umbra twenty years after two devastating earthquakes occurred in 1997. The research represents a first attempt that aims at analysing if the implemented reconstruction strategies have made the urban system more resilient with respect to both the built and the socio-economic environment.
\end{abstract}




\section{INTRODUCTION}

Almost all the Italian peninsula is a seismic prone area where one third of the population live into 5.4 million vulnerable buildings [6]. Controversially, an urban or territorial planning project specifically oriented to seismic risk mitigation has not been yet consolidated in Italy. The authors observed that interruption of the urban system functionality due to severe structural damages is one of the most evident aspects in all the main Italian earthquakes [6]. Among the causes, the seismic vulnerability of existing buildings, the lack of risk mitigation policies at the urban scale and the absence of a clear and robust recovery framework, affected all the events. The authors believe that a good reconstruction programme depends not only on improvements at single building scale, despite the common public and private trends, but also on the recovery of the functionality of the urban system as a whole [7]. The relationship between resilience and post-quake recovery is evident if resilience is assumed as the capacity of a system to withstand shocks in terms of recovery or improvement of pre-event conditions and of adaptation and reorganization of the new post-event configuration. Based on that, a simple concept can be coined: as much the system responds positively to the shock as more resilient that system is. On the base of this assumption, the knowledge of the pre-event conditions, in terms of hazard, vulnerability and exposure, is fundamental to assess the response capacity of the urban system after the seismic event. The town of Nocera Umbra, that was hit by two destructive earthquakes the $26^{\text {th }}$ September 1997, has been chosen as case study for this research, that aims, through an interdisciplinary approach among urban

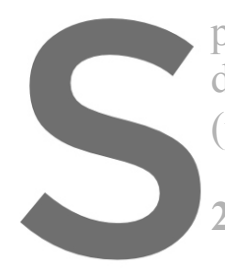
planning, engineering and geology, to explore two of the
defining urban resilience: disaster's severity (damage con
(planning framework, reconstruction strategy and governance)
2 LITERATURE REVIEW - FRAMING RESILIENC

As a unique and shared definition of resilience is not yet coined, especially in the context

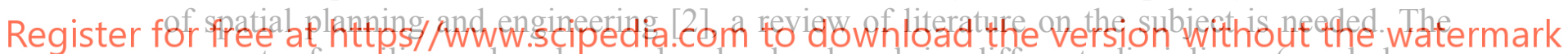
concept of resilience has been already developed in different disciplines (psychology, ecology, social science, economics and engineering) since the 70's. Due to the multidisciplinary nature of resilience, mostly fragmented literature focused on natural risks has been produced [4].

Resilience was initially used to define a measure of the persistence of systems and the ability of a system to absorb change and disturbance and still maintain the same relationships between population or state variables [8]. Later, it was defined as the ability of a system to return to its optimal condition in a short period of time [9] or reach advancements [10], after the shock. In the constellation of existing literature is possible to assert that the main difference defining resilience emerges between the engineering approach and the ecological one $[3,4]$. The first perspective considers resilience as the ability of a system to recover towards a previous or an improved stable state [11]; while the second perspective as a given ecosystem capacity to reorganize and manage changes in order to maintain the same structure and functions [12]. About this second perspective, an ambitious theoretical perspective was framed by Holling [12] and Gunderson et al. [13], the adaptive cycle: a hierarchical crossscale structure where natural and human systems are linked in a continuous adaptive cycle of growth (exploitation), accumulation (conservation), release (collapse) and renewal 
(reorganization). In their view resilience potentially depends on these four different phases. What is interesting about the concept of the adaptive cycle, is the relation between space and time scale, considering that in all systems adaptation and transformations occur as multiscalar (spatial and temporal) process [2].

However, in the hazard arena most of the resilience models involved engineered systems [4] that consider robustness, redundancy, resourcefulness, rapidity as fundamental characteristics that define the failure behaviour [11]. As claimed by Cutter et al. [4], these frameworks often fail in capturing pre-event conditions that occur at the local level or to account for the vulnerability or resilience of the environment. This work analyses the two different approaches as separated but often linked theoretical perspectives. Sharing the assumption that resilience has two different qualities: inherent (positive behaviour during non-crisis period) and adaptive (flexibility in response during seismic events) [4], the authors considers resilience as a dynamic process dependent on: 1) pre-event conditions, 2) disaster's severity (damage condition) 3) time(s), the temporal scale from the emergency response and the long-term recovery phase, 4) influences from exogenous factors (planning framework, governance and organizational capacity) during the temporal scale of interest.

\section{THE CASE STUDY: NOCERA UMBRA}

Nocera Umbra is a small historical town located within the province of Perugia (Umbria Region), Italy. Within the municipality boundaries, an historical centre surrounded by recent periphery and several Apennine municipalitie and Marche (two Italia GMT and $\mathrm{MW}=6.0$ considerably damaged.
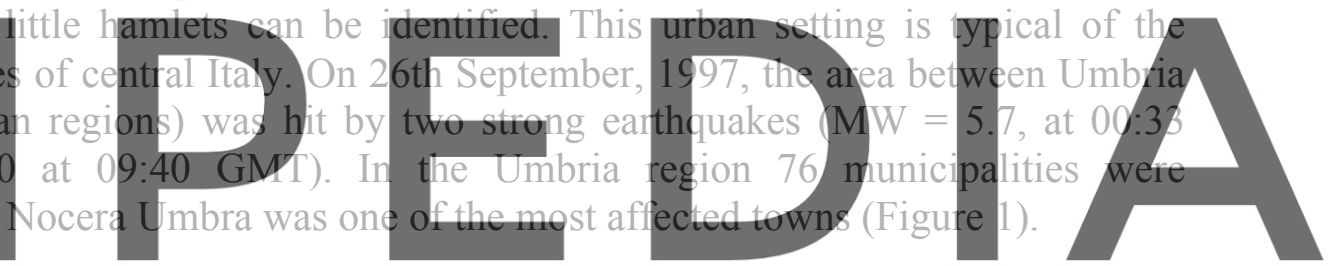

\section{Register for free at https//www.scipedia.com to download the version without the watermark}

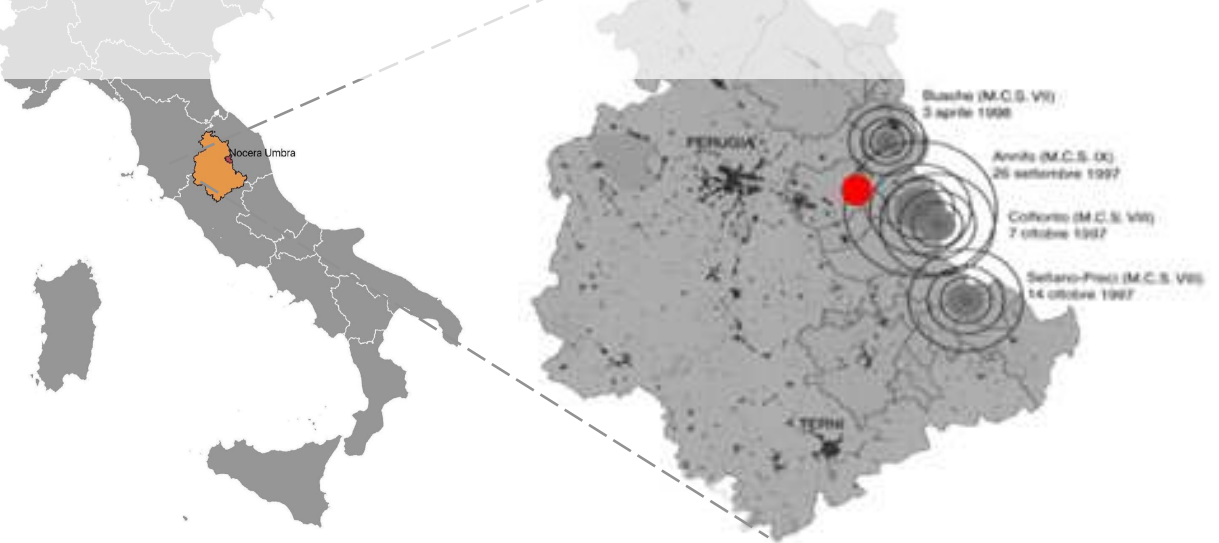

Figure 1: Umbria Region in Italian territory and epicentral area of 1997-1998 Umbria - Marche seismic sequence. The red circle represents the location of Nocera Umbra. [15]

During the decades before the earthquake, the municipality of Nocera Umbra, as well as other small towns in that region and along the Apennines, was experiencing some socio economics processes: the switch from an agricultural based economy until the ' 70 s to the current more 
industrial and tertiary (non-market services) economic profile. By analysing the variation before and after the two seismic events, while the industrial sector did not experience a significant variation, the agriculture sector decreased from $12,9 \%$ to $4 \%$, while on the opposite, the market service sector has incremented from $11,8 \%$ to $18,3 \%$.

Nocera Umbra municipality has been affected by a depopulation process over decades. An amount of 8.853 inhabitants in 1951 decreased up to the current number of 5.680 inhabitants that corresponds to the population density of 36 inhabitants per square kilometre even if this trend can be considered stable since 1971.

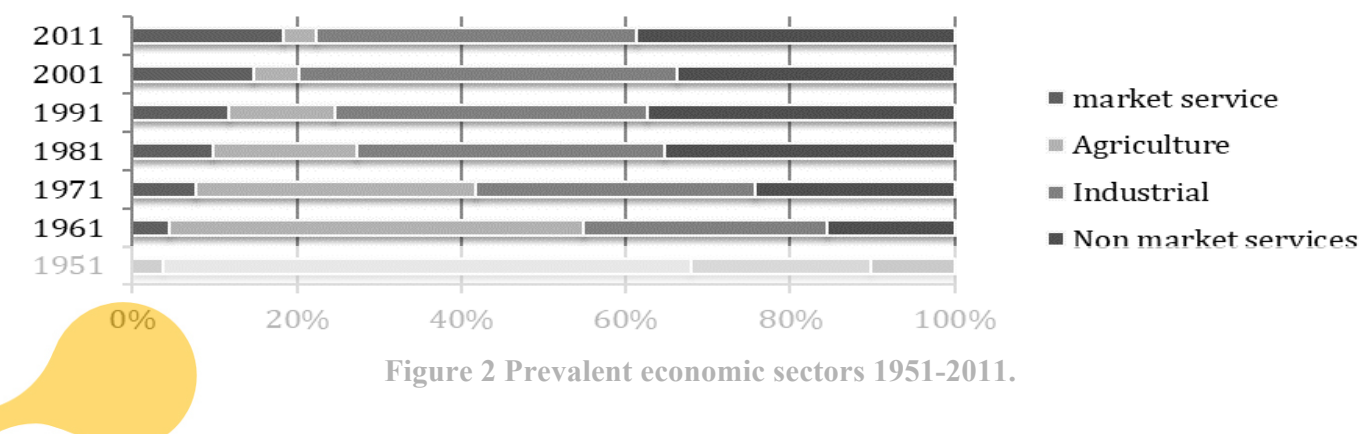

\subsection{THE DAMAGE CONDITION}

The so-called Umbrian-Marchigiana sequence hit the Central Italy area between September 1997 and April 1998. The reconstructed macroseismic field evidences peaks equal to the IX degree of the MCS scale (Mercalli-Caneani-Sieberg), related to the two earthquakes of 26th September $1997(\mathrm{MW}=5.7$, at 00:33 GMT, and MV of the relatively modest from two epicentres were recorded close to Nocera U mbra as consecuento to local geological conditions of the area.

Register for free at https//www.scipedia.com to download the version without the watermark

\begin{tabular}{|c|c|c|c|}
\hline Event & & $1^{\mathrm{ST}}$ & $2^{\mathrm{ND}}$ \\
\hline ID ITACA & & IT-1997-0004 & IT-1997-0006 \\
\hline Data & & 1997-09-26 00:33:11 & $1997-09-2609: 40: 24$ \\
\hline Lat. & & 43.02300 & 43.03100 \\
\hline Long. & & 12.89200 & 12.86200 \\
\hline Deep & {$[\mathrm{Km}]$} & 5.7 & 5.7 \\
\hline ML & & 5.6 & 5.8 \\
\hline MW & & 5.7 & 6 \\
\hline Station & & NCR & NCR \\
\hline Soil Class EC8 & & $\mathrm{E}$ & $\mathrm{E}$ \\
\hline Epicenter Distance & {$[\mathrm{km}]$} & 13.2 & 10.9 \\
\hline Azimuth & {$\left[{ }^{\circ}\right]$} & 138.3 & 144.8 \\
\hline PGA & {$[\mathrm{cm} / \mathrm{s} 2]$} & 387.399 & 492.165 \\
\hline PGV & {$[\mathrm{cm} / \mathrm{s}]$} & 12.676 & 32.574 \\
\hline PGD & {$[\mathrm{cm}]$} & 1.893 & 2.601 \\
\hline
\end{tabular}

Table 1 reports some of the properties of the two events. It is worth noting that the two Seismic Stations are placed on Soil Class E (EuroCode8). The linear distance between the 
epicentre and the seismic station is expressed in $\mathrm{km}$. The azimuth defines the strike of seismogenic fault planes and it is expressed in decimal degrees. Lastly, the peak ground acceleration (PGA), velocity (PGV) and displacements (PGD) are expressed in centimetres and seconds.

Considering the map of the damages of Nocera Umbra and other close villages [17], a not uniform damage distribution in the area is noticed. Moreover, the site amplification effects, depending on the heterogeneous subsurface geological model structure, must be considered in the damage analysis [16].

The seismic amplifications were estimated by seismic microzonation studies carried out in Nocera Umbra [17, 18]. According to the data, relevant local seismic site amplifications affected extended areas. As an effect of unfavourable geological conditions related to alluvial and colluvial cover terrain, several buildings were heavily damaged or completely destroyed (e.g. the Isola and Nocera Scalo hamlets). On the contrary, despite the historical centre of Nocera Umbra was characterized by a high vulnerability of the buildings, no collapses occurred, probably as a consequence of the discrete condition of the geological substratum. Around the historical city centre collapses and damages affected historical structures and modern buildings that were designed according to the seismic code of that period. The high values of PGA registered by the NCR stations were caused by the amplification of ground motion due to adverse geological conditions related to contact (about $7 \mathrm{~m}$ deep) between alluvial cover deposits and weathered geological substratum on geological bedrock [19]. The high damage levels of Nocera Scalo area, an inhabited centre severely struck by the seismic sequence of 1997 , is cor conditions consisting of This data suggest a great influence of site effe geological context [30] In Figure 3 the earthqua Umbra are expressed in
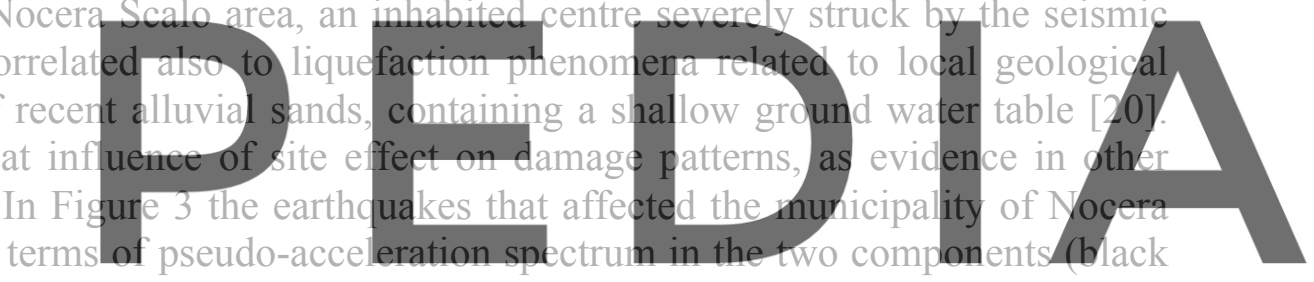

continuous line HNN direction and dots line HNE) in comparison to those obtained by all the

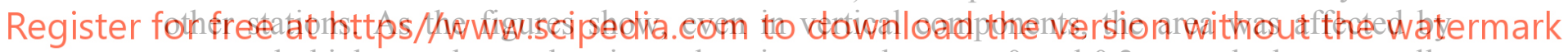
extremely high pseudo acceleration values in range between 0 and 0,2 seconds that generally mark small masonry buildings widely spread in all the Italian territory.

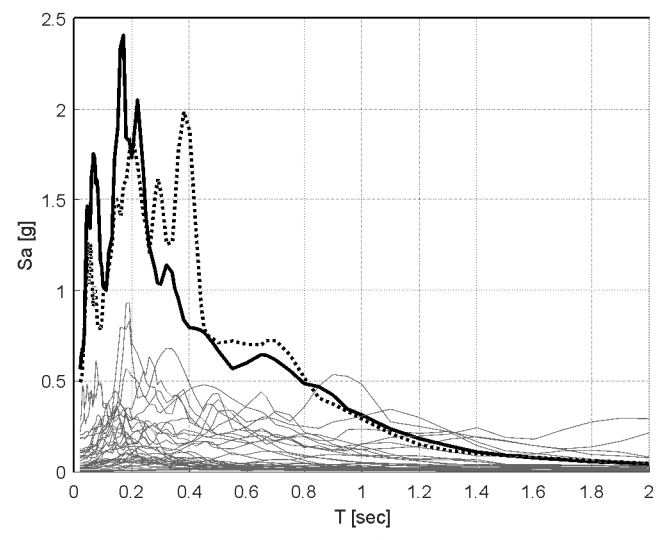

a)

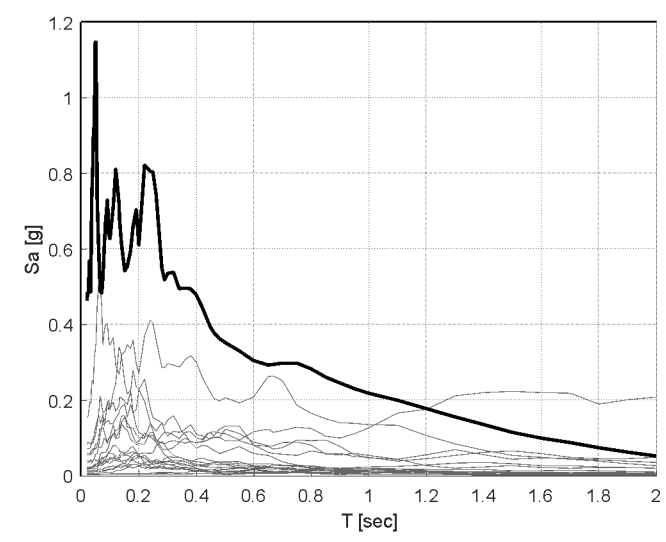

b)

Figure 3: Main shock $\left(2^{\text {nd }}\right)$ response spectra in a) horizontal and b) vertical components 
Other authors carried out research on the damaged structures that were struck by the two earthquakes [21]. The authors are aware that the seismic response of masonry structures cannot be described by single structural detail but by the interdependency of all the structural details. In this paper a novel approach is proposed. Each structure is considered in terms of discrepancy from a structural prototype. The prototype is an ideal building characterised by optimal properties that play a fundamental role in the seismic behaviour and can define, ideally, small or neglectable seismic vulnerability. The surveys [22] that were carried out in post-event condition identified the structural characteristics and damages by means of a fast procedure. The procedure was based on a form that assigned different weights to all the possible structural properties of the buildings. Some of these properties have been considered as fundamental in this work and adopted in the next equation. The authors, inspired by basic concepts of nature, namely genes and chromosomes, adopted the above mentioned terms for defining an "optimal gene" that may represent a low vulnerable masonry building [23, 24]. On the other hand, on the base of the same "chromosomes", each building can be defined by its own genes. The aim is to establish a "discrepancy index" that can globally describe the structures and their propensity to damage.

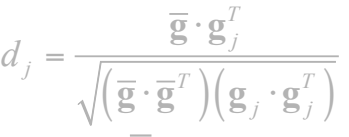

In the previous equation the symbols $\bar{g}$ and $g_{j}$ are the "optimal gene" and the $\mathrm{j}$-th "building gene", respectively. The index, that is part of an ongoing research, does not
consider different weights for each structural property. The aim is to understand if, globally,
all the elements can contribute to the level of damage and if the propension to damage can be
expressed without a-priori weights. The presence, or absence, of the following characteristics
has been considered: foundations, masonry typology, mortar quality, presence/absence of i)
edge beams at floor or roof levels, ii) corners, iii) connections between floors and wdlls, iv)

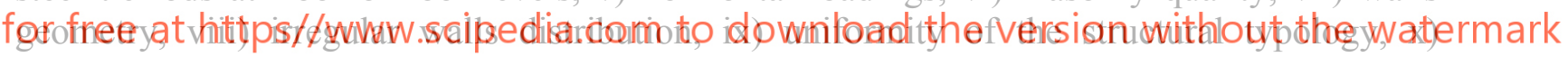
relevant structural defects. With regard to the buildings that were included in IRP acronym for Integrated Recovery Programmes IRP (L. n. 61/98, L.R. n.15/9) project and on the base of surveys [22] the following histograms show how the structures that were hit by the two earthquakes were majorly marked by low discrepancy indices that represent structures with non-optimal structural properties. The Damage Levels can be synthetized as in the following. Level 1 or Significant Damage. This is defined by cracks and crushes that involve the $30 \%$ of structural elements at least. Level 2 or Heavy Damage. Shear cracks in the $30 \%$ of structural elements, compressive crushes in 5\% of the structural elements, collapse of $5 \%$ of the entire building area, out-of-plane displacements up to $5 \mathrm{~cm}$, foundation failures, hydrogeological issues. Level 3 or Extremely Heavy Damage. Shear cracks in the $30 \%$ of structural elements of $10 \mathrm{~mm}$, compressive crushes in $10 \%$ of the structural elements, collapse of $20 \%$ of the entire building area, out-of-plane displacements up to $10 \mathrm{~cm}$, foundation failures, hydrogeological issues. Level 4 or Collapse Damage. Collapse of more than $30 \%$ of the building. All the analysed structures reported heavy structural deficiencies that probably determined the collapses or damages even in case of unitary discrepancy index, as in Figure 4.b is evident in case of Damage Levels 1 and 2. All the structures that were part of the IRP project were affected by heavy structural deficiencies. The index is part of an on-going 
research and the authors are aware that additional comparisons with other real cases are necessary.
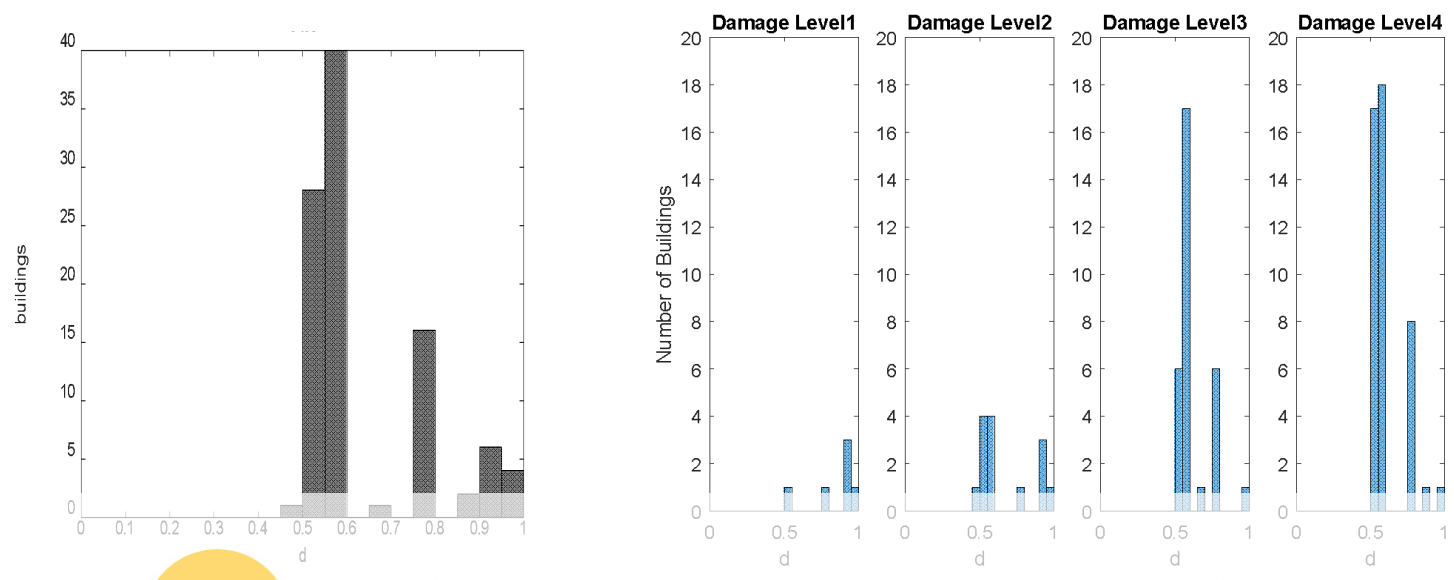

a)

b)

Figure 4: Discrepancy indices of the a) IRP buildings and b) divided in order to the reached damage levels

3.2 THE RECONSTRUCTION FRAMEWORK

Although some buildings collapsed as a consequence of the two earthquakes, there were no casualties. Nevertheless

Immediately after th

have been an opportun ty

quality of the urban fab

vulnerability of local co

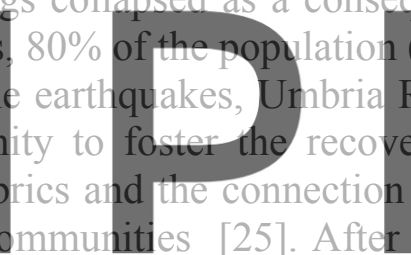

$n(4,499$ inhabita
Region claimed
very of the econ
$n$ among the sett

the decision-making process have developed the reconstruction model around three main

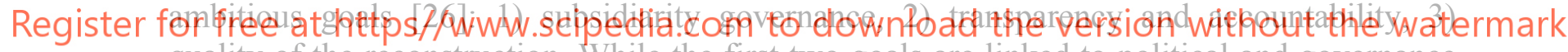

quality of the reconstruction. While the first two goals are linked to political and governance

issues, the third one is strictly related to spatial and physical reconstruction. Through this

goal the actors in charge of the reconstruction process aimed from the beginning at preserving the urban legacy of the damaged settlements, together with the cultural and social identity of their communities [26]. The paradigm was 'how it was, where it was'. The reconstruction strategies were based on three macro categories: i) Light reconstruction (OCD n.61, 1997) (i.e. restoration of buildings that were relatively not massively damaged); ii) Heavy reconstruction (L. n.61/98, LR n.30/98, DGR n.5180/98) (i.e. reconstruction of severely damaged isolated buildings, limited to those located outside the integrated recovery programmes); iii) Integrated reconstruction (L. n. 61/98) (i.e. restoration of the historical cores, in terms of architectural and landscape heritage, and socio-economic conditions). The latter represents the most interesting experience and involved more than $40 \%$ of the building stock. The integrated reconstruction was implemented through the Integrated Recovery Programmes (IRP). The IRP are planned as tools for programmatic and financial coordination with two purposes: 1) ensure the unitary and coordinated implementation of intervention on private and public buildings, the infrastructural setting and the public spaces; 2) prevent the most affected areas, mainly inner areas or depopulated villages, from becoming abandoned 
and vacant. The Reconstruction Observatory that was established for monitoring all the reconstruction process claimed that even though IRP programmes cannot be considered directly as instruments for economic and social development, they can actually act as flywheel to revitalize the villages towards a new economic recovery and re-settlement [14]. From these premise, Umbria Region activated 185 IRP in 22 municipalities of which 41 in the municipality of Nocera Umbra (Figure 5.a). One of the IRP corresponded to the perimeter of the entire historical centre (Figure 5.b).

In order to define the IRP perimeter, the area, any historical urban or rural core or village, should have had at least one of three main features: i) historical and monumental value; ii) landscape or environmental value; iii) socio-economic issues related to post-earthquake needs. Every IRP projects area were composed of both private and public buildings and infrastructures that hosted different urban functions: housing, public services and public spaces, economic activities, social and cultural places and buildings. The interventions on public, private or mixed properties, included within the perimeter area, were organized in Minimum Intervention Units, whose sizing took into account the unitary needs of the organization of interventions under the structural, technical, economic, architectural and urban profile [14]. The innovative aspect of IRP programmes was the aggregation of single buildings towards a systemic urban vision and the definition of recovery mechanism as a dynamic process.
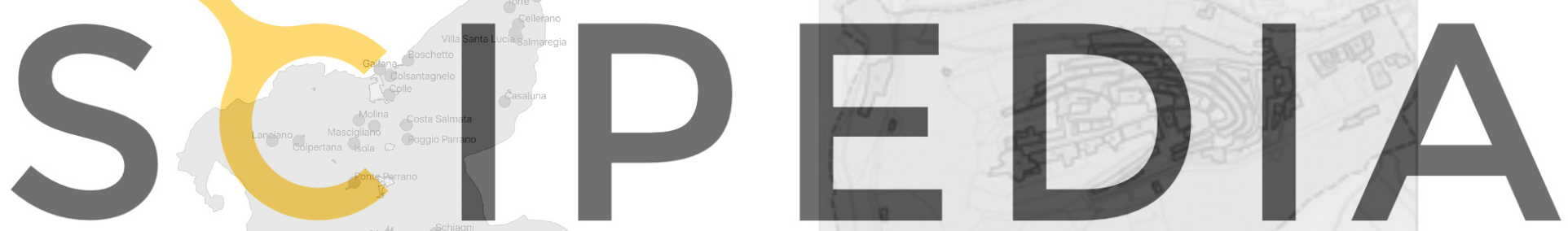

Register for free at https//www.scipedifancteom to download the version without the watermark

a)

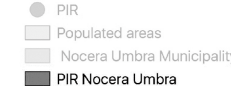

PIR Nocera Umbra

Figure 5: Spatial distribution of IRP within a) the boundaries of Nocera Umbra municipalities and b Nocera Umbra Historical centre). (Reconstruction Observatory. Last access, January 2020. Modified)

\section{NOCERA UMBRA TWENTY YEARS AFTER}

After more than twenty year, some considerations on the reconstruction model and its implementation can be framed: 623 interventions of heavy reconstruction (97\%) and 220 of the light (100\%) have been concluded. According to the Reconstruction Observatory, 41 IRP have been activated until july 2018, in the Municipality of Nocera Umbra, with an amount of 387 interventions activated, 429 started and 388 concluded (90\%). In terms of public buildings 20 upon 25 interventions $(80 \%)$ have been concluded. While for the cultural heritage the $11 \%$ still have to be activated (Figure 7). Generally, even some buildings have to be still reconstructed, the process seems characterized by a satisfactory equilibrium between quality and velocity of the reconstruction [25]. The paradigm "how it was, where it was" has prevented, mainly in the sprawled environment and in the little villages, the triggering of 
further process of abandonment, in a territory already heavily affected by depopulation issues [27]. The IRP programme, that was essentially a financial and programmatic project that did not take directly into consideration spatial planning considerations, has represented one of the most innovative reconstruction instruments.

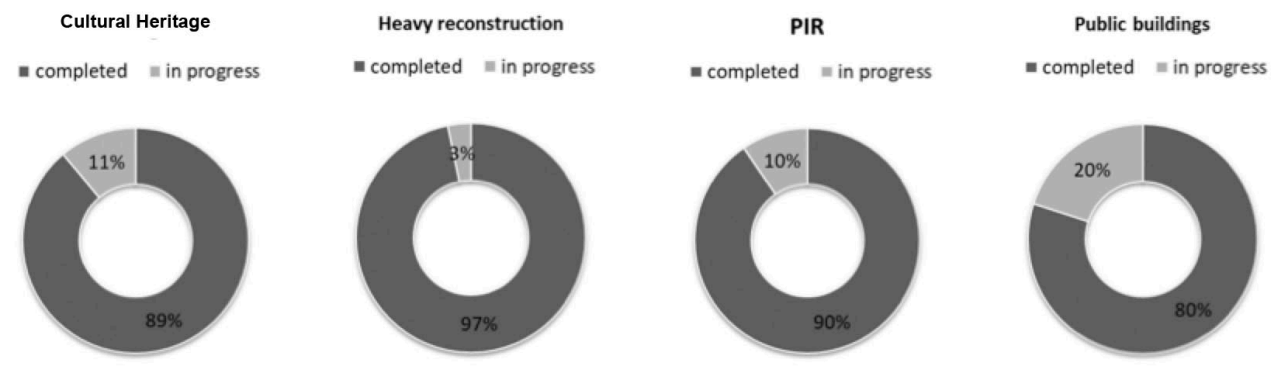

Figure 7: State of the reconstruction. Elaboration by the authors on Reconstruction Observatory data

The Umbria reconstruction strategy produced a complex but coordinated series of interventions, both on private and public building, having also considered the infrastructural and public space systems. Moreover, for the first time after a major earthquake in Italy, the complexity of the post-quake reconstruction of historical centres was recognized, understanding that all the recovery operations should have been planned in an integrated way, through the involvement of different aspects: private and public buildings, cultural heritage, infrastructural systems, and geo instabilities [28]. In this sense the IRP experience could be
considered a valid effort in terms of reinforcing urbar resilience and testing the response capacity of the local actors in coordination of IRP projects 1 moving the scale on a guarantee the same conditions Additionally, even in the same region, in some nun
omplex and large urban systern, the same structure the IRP programmes have been recognized as best practices, while in some others, such as

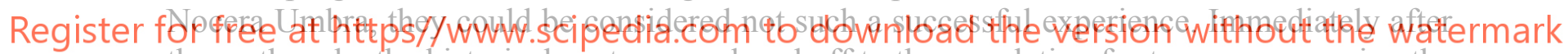
the earthquake the historical centre was closed off to the population for two years, causing the abandon of the old town. The main facilities were dislocated in the outskirts, where people were temporarily living. The reconstruction of Nocera Umbra followed the same strategy of all the other municipalities but experienced several delays due to different factors, such as the lack of IRP coordination and the slow restoration of the historical centre that has been concluded 15 years after only. The historical centre was totally renewed, but depopulated [29]. According to other authors [26] several critical aspects influenced the reconstruction of Nocera Umbra negatively: 1) the structural complexity of the interconnected buildings in the historical centre, that increased the difficulty in establishing the owners unions required for the constitution of the IRP perimeters; 2) the issue of private property owners, because many of the building owners did not dwell in the Municipality of Nocera Umbra, so were not able to follow closely the process; 3) the general lack of institutional capacity of the actors involved in the processes.

\section{CONCLUSION}

The paper analyses the case study of Nocera Umbra that was hit by devastating earthquakes in 1997 in order to provide a first assessment of the post- earthquake 
reconstruction considering two scale of analysis: the single building scale and the broader urban one. Resilience offers a significant paradigm to gain a better understanding in reading the capacity of a system to respond to shocks, mainly in terms of analysis of the damage conditions and the exogenous factors (such as the reconstruction planning framework and the reconstruction governance). Authors focused mainly on the analysis of the reconstruction process and strategies, and their effects on the urban system. In terms of vulnerability of the building heritage, the authors proposed a speditive vulnerability index. The idea is to compare each building with a less vulnerable prototype by means of key features establishing a discrepancy value. This is part of an on-going research and more data and validation are needed. On the other hand, the index can be easily adapted and more terms can be considered in view of geological effects on structures or, more generally, resilience porpoises. Since the research is still ongoing, it is possible to outline only preliminary conclusions, and authors are aware that additional data research, analysis and comparisons with other real cases are needed. About data analysis, one of the issues is the poor quality and the absence in many cases of data before 1997. The consequence is the difficulty to compare the pre- and postphase, both in terms of physical-spatial and socio-economic outcomes. Nevertheless, is anyway possible to go to some preliminarily conclusive points. Nocera Umbra constitutes an interesting case study that is worth observing. Beside the critical aspects that influenced negatively the reconstruction of Nocera Umbra, the Umbria reconstruction experience was important for post-earthquake Italian cases. It aroused attention to prevention and mitigation seismic risk, in terms of urban and regional planning. For instance, the Regional Law n.11/2005 obliges all th Structure) in the genera programmes and, on or mitigation issues and, seismic risk mitigation and tetritorial planning consider critical the analysis of real cases as useful tool for the development of effective

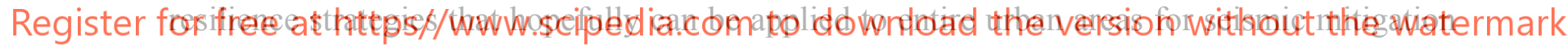
purposes.

\section{Acknowledgments}

This research was supported by the Italian Department for Civil Protection (DPC) within the "PON Governance 2014-2020 project on the reduction of seismic, volcanic and hydrogeological risk for civil protection purposes - CIG 6980737E65 - CUP J59G16000160006" (Scientific coordinator for CNR, Massimiliano Moscatelli). Authors would like to thank Fabrizio Bramerini, Sergio Castenetto, Antonella Gorini, Giuseppe Naso, and Daniele Spina (all of them from DPC; F.B. coordinator) for the useful discussions.

\section{REFERENCES}

[1] E. Quarantelli, "Converting disaster scholarship into effective disaster planning and managing: possibilities and limitations," International Journal of Mass Emergencies and Disasters, vol. 11, pp. 15-39, 1993.

[2] L. Chelleri, J. Waters, M. Olazabal and G. Minucci, "Resilience trade-offs: addressing multiple scales and temporal aspects of urban resilience," Environment and 
Urbanization, vol. 27, no. 1, pp. 181-198, 2015.

[3] G. Cimellaro, C. Renschler, A. Reinhorn and L. Arendt, "PEOPLES: A framework for evaluating resilience.," Journal of Structural Engineering, vol. 142, no. 10, 2016.

[4] S. Cutter, L. Barens, M. Berry, C. Burton, E. Evans, E. Tate and J. Webb, "A placebased model for understanding community resilience to natural disasters," Global environmental change, vol. 18, no. 4, pp. 598-606, 2008.

[5] O. Kammouh, A. Zamani Noori, G. Cimellaro and S. Mahin, "Resilience Assessment of Urban Communities," SCE-ASME Journal of Risk Uncertainty Engineering System, Part A: Civ. Eng.,, vol. 5, no. 1, 2019.

[6] CRESME, "Rapporto sullo stato di rischio del territorio italiano," Rome, 2017.

[7] A. Fiore, C. Suplizio, C. Demartino, I. Vanzi, S. Biondi and V. Fabietti, "Seismic vulnerability assessment of historical centers at urban scale," International Journal of Architectural Heritage. Conservation, Analysis and Restoration, vol. 12, no. 2, pp. 257269, 2018.

[8] C. Holling, "Resilience and stability of ecological systems," Annual Review of Ecology, Evolution and Systematics, vol. 4, no. 1, p. 1-23, 1973.

[9] Y. Haimes, "On the definition of resilience in systems," Risk Analysis, vol. 29, no. 4, pp. 498-501, 2009.

[10] C. Folke, "Resilience: the emergence of a perspective for social-ecological systems analysis," Global Environmental Change, vol. 16, no. 3, pp. 253-267, 2006.

[11] M. Bruneau, S. Chang, R. Eguchi, G. Lee, T. O’Rourke, A. Reinhorn, M. Shinozuka, K. Tierney, W. Wallace and D. von Winterfeldt, "A framework to quantitatively assess and enhance the seismic resilience of communities," Earthquake Spectra, vol. 19, no. 4, pp. 733-752, 2003.

[12] C. Holling, "Understanding the Complexity of Economic, Ecological, and Social Systems.," Ecosystems, vol. 4, pp. 390-405, 2001.

[13] C. Gunderson, J. Holling, G. Pritchard and L. Peterson, Resilience of large-scale resource systems, Washington, DC: Island Press, 2002.

[14] Osservatorio sulla ricostruzione, "Osservatorio sulla ricostruzione," [Online]. Available: http://www.osservatorioricostruzione.regione.umbria.it. [Accessed 12 February 2020].

[15] INGV, "ITACA - Italian Accelerometric Archive," [Online]. Available: itaca.mi.ingv.it.

[16] S. Catalano, S. Grassi, S. Imposa, G. Tortorici, G. Cavuoto, V. Di Fiore, G. Alleanza, A. Chiaradonna, F. de Silva, A. d'Onofrio, F. Silvestri and G. Romagnoli, "The subsoil model for seismic microzonation study: the interplay between geology, geophysics and geotechnical engineering.," Geotechnical Engineering for Protection and Development of Environment and Constructions, 2019.

[17] M. A., "Microzonazione sismica di Nocera Umbra. Rapporto UMSEG,," 1998.

[18] F. Bozzano, F. Parroni, P. Traversa and G. Valentini, Geological engineering input data for microzonation of Nocera Umbra Commune, Vols. RIG, Special Issue on Umbria Marches Earthquakes of 1997, 2000.

[19] T. Crespellani, C. Madiai, G. Simoni and G. Vannucchi, "Dynamic geotechnical testing and seismic response analysis in two sites of the Commune of Nocera Umbra, Italy.," Rivista Italiana di Geotecnica, vol. 4, 2001. 
[20] T. Crespellani, C. Madiai and G. Vannucchi, "Liquefaction risk analysis during earthquakes at Nocera Scalo, Italy, Part I: Assessment of liquefaction potential using simplified procedures.," Italian Geotechnical Journal, no. 4, pp. 24-45, 2002.

[21] P. Angeletti, F. Baciucco, M. Barluzzi, P. Battisti, P. Macaluso, P. Materazzi and R. Panella, "Confronto fra danni, vulnerabilità ed interventi di consolidamento.Il caso dell'Umbria negli eventi sismici del 1997-1998," in ANIDIS.

[22] Regione Umbria, "Comitato Tecnico Scientifico (istituito con Ordinanza n.2669/97) Interventi di ricostruzione degli edifici distrutti e di ripristino con miglioramento sismico SCHEDE TECNICHE DI ACCOMPAGNAMENTO AL PROGETTO,” 1997.

[23] E. César Javier Chácara, C. Francesco, C. Francesco, P. Bartolomeo and L. Paulo B., "Seismic vulnerability of URM structures based on a Discrete Macro-Element Modeling (DMEM) approach," Engineering Structures, vol. 201, September 2019.

[24] A. Greco, G. Lombardo, B. Pantò and A. Famà, "Seismic Vulnerability of Historical Masonry Aggregate Buildings in Oriental Sicily," International Journal of Architectural Heritage, December 2018.

[25] G. Nigro, "La ricostruzione dopo il terremoto," Urbanistica Informazioni, vol. 226, pp. 22-24, 2009.

[26] R. Segatori, "La ricostruzione post-sismica in Umbria come modello di governance," Oltre la ricostruzione, vol. 5, 2007.

[27] M. Sartore, "Umbria 1997. Ricostruire "dov'era, com'era". Ma basta?," Lente d'ingrandimento, 2009.

[28] S. Bosi and A. Moretti, "Programmazione e strumentazione urbanistica," Urbanistica Informazioni, vol. 226, pp. 24-26, 2009.

[29] G. Bicchieri, Pianificare la temporaneità. Storie di gestione e autogestione nel post sisma del centro Italia, Torino: Tesi di laurea, Politecnico di Torino, Laurea Magistrale in Pianificazione territoriale urbanistica e paesaggio ambientale, AA 2017/2018.

[30] F. Panzera, G. Lombardo, S. Imposa, S. Grassi, S. Gresta, S. Catalano, G. Romagnoli, G. Tortorici, F. Patti, E. Di Maio, "Correlation between earthquake damage and seismic site effects: the study case of Lentini and Carlentini, Italy". Eng. Geol. 240, 149-162. 2018 